\title{
Body Composition, Hemodynamic, and Biochemical Parameters of Young Female Normal-Weight Oligo-Amenorrheic and Eumenorrheic Athletes and Nonathletes
}

\author{
Vibha Singhal ${ }^{a, c, d}$ Maria de Lourdes Eguiguren ${ }^{a, c}$ Lindsey Eisenbach ${ }^{a, c}$ \\ Hannah Clarke ${ }^{a, c}$ Meghan Slattery ${ }^{a, c}$ Kamryn Eddy ${ }^{b}$ Kathryn E. Ackerman ${ }^{a, c, e}$ \\ Madhusmita Misraa, c, d \\ ${ }^{a}$ Neuroendocrine Unit and b Harris Center, Massachusetts General Hospital, ' Harvard Medical School, \\ dPediatric Endocrine Unit, Massachusetts General Hospital for Children, and eDivision of Sports Medicine, \\ Boston Children's Hospital, Boston, Mass., USA
}

\section{Key Words}

Athletes $\cdot$ Adolescents $\cdot$ Bone density $\cdot$ Body composition .

Hormones · Liver function tests $\cdot$ Heart rate $\cdot$ Blood

pressure $\cdot$ Hematological tests

\begin{abstract}
Aims: Low-weight hypogonadal conditions such as anorexia nervosa are associated with marked changes in body composition, hemodynamic and hematological parameters, and liver enzymes. The impact of athletic activity in normal-weight adolescents with/without amenorrhea on these parameters has not been assessed. Our aim was to examine these parameters in normal-weight athletes and nonathletes and determine any associations with body composition, oligo-amenorrhea, and exercise intensity. Methods: We assessed vital signs, complete blood counts, liver enzymes, and regional body composition in 43 oligo-amenorrheic athletes (OAA), 24 eumenorrheic athletes (EA), and 23 nonathletes aged 14-21 years. Results: The BMI was lower in OAA than in EA. Systolic and pulse pressure and temperature were lowest in OAA. Blood counts did not differ among groups. Aspartate aminotransferase (AST) was higher in both groups of athletes, while alanine aminotransferase
\end{abstract}

(ALT) was higher in OAA than in EA and nonathletes. Total and regional fat were lower in OAA than in other groups, and these factors were associated positively with heart rate and inversely with liver enzymes. Conclusions: Athletic activity is associated with higher AST levels, whereas menstrual dysfunction is associated with lower total and regional fat and higher ALT levels. Higher liver enzymes are associated with reductions in total and regional fat.

(C) 2014 S. Karger AG, Basel

\section{Introduction}

The number of young women participating in athletics has increased markedly in recent decades [1]. Exercise has many benefits but carries risks of energy deficit when excessive $[2,3]$. The female athlete triad of low energy availability, menstrual dysfunction, and low bone mineral density is now increasingly recognized [4], with $\sim 24 \%$ of adolescent athletes demonstrating menstrual dysfunction [5]. While excessive exercise has known associations with adverse reproductive and bone outcomes $[3,6]$, there are few data regarding other adverse effects of excessive exercise and amenorrhea.

\section{KARGER}

E-Mail karger@karger.com

www.karger.com/anm
(C) 2014 S. Karger AG, Basel

0250-6807/14/0654-0264\$39.50/0
Vibha Singhal, MD

BUL 457, Neuroendocrine Unit

Massachusetts General Hospital

Boston, MA 02114 (USA)

E-Mail vsinghal1 @ partners.org 
Conditions of extreme undernutrition, such as anorexia nervosa (AN), are characterized by changes in body composition, hemodynamic and hematological parameters, and liver enzymes $[7,8]$. Changes in heart rate, systolic blood pressure (SBP), and blood flow are also described in adult amenorrheic athletes [9]. However, the impact of exercise and oligo-amenorrhea in normalweight adolescent athletes is not known. We have shown that adolescent oligo-amenorrheic athletes (OAA) (even when normal weight) have reductions in body fat that differentiate them from eumenorrheic athletes (EA) and nonathletes [10]. The associations of a reduced fat mass with hemodynamic, hematological, and biochemical parameters in this population remain to be determined.

Regular exercisers have a lower heart rate, SBP, and diastolic blood pressure (DBP) than nonexercisers [11, 12] due to their enhanced parasympathetic tone [13]. Similar changes are observed with severe energy deprivation, as in AN [8]. However, data are lacking regarding hemodynamic parameters in young adolescent normal-weight OAA compared to EA, particularly in relation to body fat. Also, blood counts may decrease with extreme undernutrition (such as in AN) $[8,14]$. Studies have not examined hematological parameters in normal-weight adolescent OAA versus $E A$, although studies in adult athletes report a high prevalence of dilutional pseudoanemia in this population [reviewed in 15]. Finally, although most athletes do not have significant biochemical abnormalities on prescreening evaluations [16], their liver enzymes are sometimes elevated. In fact, liver enzymes are elevated at the extremes of the nutritional spectrum, in fatty liver disease from visceral adiposity [17] and related to malnutrition in AN $[7,18]$. Data are lacking regarding associations of chronic exercise and amenorrhea with liver enzymes in relation to body fat (a surrogate for energy stores).

Our objective was to examine hemodynamic and hematologic parameters and liver enzymes in normalweight athletes and nonathletes aged $14-21$ years and determine the associations of body composition, oligoamenorrhea, and intensity of exercise with these parameters. We hypothesized that OAA would have greater impairment of these parameters than EA and nonathletes related to their lower body fat (a reflection of energy stores).

\section{Methods}

Subjects were recruited from medical clinics, newspapers, and colleges. We enrolled 43 OAA, 24 EA, and 23 nonathletes aged $14-21$ years. The training criteria for athletes were $\geq 20$ miles/week of running or $\geq 4 \mathrm{~h} /$ week of weight-bearing training for $\geq 6$ months in the past year. The inclusion criteria for nonathletes were $<2$ $\mathrm{h}$ /week of weight-bearing activity. Oligo-amenorrhea was defined as the absence of menses for at least 3 months within a $\geq 6$-month period of oligomenorrhea (cycle length $>6$ weeks) or the absence of menarche at $>16$ years. Three subjects aged $15.1-16.8$ years had not attained menarche, and other causes of menarchal delay were ruled out. Eumenorrhea was defined as $\geq 9$ menses (cycle length 21-35 days) in the previous year. All subjects had a bone age $\geq 14$ years and BMI between the 10th and 90th percentiles. Other causes of amenorrhea such as medications affecting the hypothalamicpituitary-ovarian axis (including oral contraceptives and hormone replacement), hyperprolactinemia, ovarian failure, polycystic ovary syndrome, and thyroid dysfunction were ruled out. This study was approved by the Partners HealthCare Institutional Review Board. Informed consent was obtained from subjects aged $\geq 18$ years and the parents of subjects aged $<18$ years. Informed assent was obtained from girls $<18$ years.

Weight was measured on a single electronic scale with subjects wearing a hospital gown, and height was recorded as an average of 3 measurements on a single wall-mounted stadiometer. BMI was calculated as weight $(\mathrm{kg}) /$ height $(\mathrm{m})^{2}$. The percent ideal body weight was calculated using the BMI percentile method. Bone age was assessed from a left-hand radiograph [19]. A detailed exercise history was obtained to calculate the activity level (h/week of athletic activity over 12 months). Resting energy expenditure (REE) was measured by indirect calorimetry (VMAX Encore 29 metabolic cart; Viasys Healthcare, San Diego, Calif., USA). Blood pressure was measured using an aneroid sphygmomanometer after adjusting the cuff size in a sitting position. Pulse pressure was calculated as the difference between the SBP and the DBP. Pulse was measured manually and temperature with an infrared tympanic thermometer in a standardized fashion. Complete blood counts were analyzed in the hospital laboratory $\left(\right.$ Sysmex ${ }^{\circledR} \mathrm{X}$-series analyzer), and potassium and liver function were assessed by LabCorp using standard methods (Roche/Hitachi MODULAR ${ }^{\circledR} \mathrm{P} / \mathrm{D}$ Analyzers). All subjects were interviewed by the study psychologist for disordered eating behavior and were administered two questionnaires to assess eating behaviors, i.e. the Eating Disorders Inventory-2 and the Three-Factor Eating Questionnaire.

Waist and hip measurements were taken standing using a plastic tape measure to the nearest $0.1 \mathrm{~cm}$ at the end of expiration. The waist-to-hip ratio was calculated as the waist measurement at the iliac crest divided by the greatest hip circumference. We used dual energy X-ray absorptiometry (Hologic Discovery A; Waltham, Mass., USA; software version APEX 3.3) to measure the percent body fat and regional fat and the lean mass. Trunk/extremity fat was calculated by dividing trunk fat by total extremity fat. The coefficients of variation for lean and fat mass were 1.0 and $2.1 \%$.

\section{Statistical Methods}

JMP Software (v10; SAS Institute, Inc., Cary, N.C., USA) was used for analysis. Results are reported as means $\pm \mathrm{SD}$. We used ANOVA to determine differences among groups for most parameters, followed by the Tukey-Kramer test to control for multiple comparisons. For nonnormally distributed parameters (AST, ALT, alkaline phosphatase, fat mass, and trunk fat) a nonparametric analysis (Kruskal-Wallis) was used followed by the Steel-Dwass test to control for multiple comparisons. Subjects were also divided into quartiles based on hours per week of exercise activity, and 
Table 1. Clinical characteristics of amenorrheic athletes, EA, and nonathletes

\begin{tabular}{|c|c|c|c|c|c|c|c|}
\hline Age, years & $19.2(2.1)$ & $18.0(2.1)$ & $19.1(1.7)$ & 0.052 & - & - & - \\
\hline Bone age, years & $17.5(1.0)$ & $17.2(1.2)$ & $17.5(1.1)$ & NS & - & - & - \\
\hline Age of menarche, years & $13.7(1.8)$ & $12.8(1.4)$ & $12.2(1.5)$ & 0.0012 & 0.06 & 0.001 & - \\
\hline Duration of amenorrhea, $\mathrm{m}$ & $9.0(13.2)$ & & & & & & \\
\hline Tanner stage (breast) & $4.6(0.7)$ & $4.7(0.6)$ & $4.8(0.6)$ & NS & - & - & - \\
\hline Weight, kg & $56.3(7.1)$ & $62.0(10.7)$ & $57.7(8.0)$ & 0.03 & 0.027 & - & - \\
\hline $\mathrm{BMI}, \mathrm{kg} / \mathrm{m}^{2}$ & $20.6(2.1)$ & $22.4(2.4)$ & $21.7(2.5)$ & 0.005 & 0.005 & - & - \\
\hline Percent ideal body weight & $96.4(9.7)$ & $107.8(13.8)$ & $102.6(13.3)$ & 0.001 & 0.0008 & - & - \\
\hline Activity level, h/week & $9.9(4.9)$ & $11.0(4.3)$ & $1.0(1.4)$ & $<0.0001$ & - & $<0.0001$ & $<0.0001$ \\
\hline REE, cal & $1,255(188)$ & $1,444(219)$ & $1,255(193)$ & 0.0007 & 0.001 & - & 0.004 \\
\hline \multicolumn{8}{|l|}{ Regional body composition } \\
\hline Trunk fat ${ }^{\mathrm{a}}, \mathrm{kg}$ & $4.7(1.8)$ & $5.6(2.2)$ & $5.7(2.1)$ & 0.051 & 0.07 & 0.028 & - \\
\hline Extremity fat, kg & $6.8(2.1)$ & $8.6(2.3)$ & $9.4(3.0)$ & 0.0002 & 0.004 & 0.0001 & - \\
\hline Trunk-to-extremity fat ratio & $0.7(0.2)$ & $0.6(0.1)$ & $0.6(0.1)$ & NS & - & - & - \\
\hline Total lean mass, kg & $43.5(5.6)$ & $46.3(7.7)$ & $40.5(4.4)$ & 0.005 & - & - & 0.003 \\
\hline Total extremity lean mass, $\mathrm{kg}$ & $19.2(2.8)$ & $21.0(3.9)$ & $18.2(2.6)$ & 0.01 & 0.026 & - & 0.003 \\
\hline
\end{tabular}

Values are expressed as means (SD). p values $\leq 0.1$ are reported. NS $=$ Not significant. ${ }^{\text {a }}$ Nonparametric testing.

variables were compared across quartiles of activity. We used Spearman's correlations to determine associations between variables, and multivariate analysis to control for confounders. Regression modeling was performed to determine predictors of liver enzymes, with a $\mathrm{p}$ value of 0.1 to enter and leave the model. We included hours/week of athletic activity, percent body fat, lean mass amenorrhea, and duration as covariates. $\mathrm{p}<0.05$ was considered statistically significant.

\section{Results}

\section{Clinical Characteristics}

Groups did not differ in terms of chronologic age, bone age, height, or Tanner stage (table 1). OAA had a lower BMI than EA, although all subjects had a BMI $>17.5$ (BMI between the 10th and the 90th percentiles). OAA had a later menarchal age than nonathletes. Thirtyfive percent of OAA reported disordered eating compared to $4.2 \%$ of EA and none of the nonathletes ( $\mathrm{p}=$ 0.0008 ). Activity level was higher in athletes versus nonathletes per protocol and did not differ between OAA and EA. REE was highest in EA, even after adjusting for lean mass.

\section{Regional Body Composition}

Waist and hip circumferences did not differ across groups (table 1). Both athlete groups had lower percent body fat values than nonathletes. Total and extremity fat were lower in OAA than in EA and nonathletes. Trunk fat was lower in OAA than in nonathletes and trended lower than in EA. However, after adjusting for total fat, OAA had higher trunk fat $(\mathrm{p}=0.006)$ values, lower extremity fat $(\mathrm{p}=0.002)$ values, and a higher trunk/extremity fat ratio $(p=0.004)$ than the other groups. EA had higher total and extremity lean masses than OAA and nonathletes.

\section{Hemodynamic, Hematological, and Biochemical Parameters}

Heart rate was lower in athletes than in nonathletes (table 2) but did not differ in OAA versus EA. SBP and pulse pressure were lower in OAA than in EA but did not differ from nonathletes. DBP did not differ among groups. Heart rate was significantly different when athletic activity quartiles were compared $(\mathrm{p}=0.0001)$, and girls in each of the upper 3 quartiles had a lower heart rate than those in the first quartile. No relationship was 
Table 2. Hemodynamic, hematological, and biochemical parameters of amenorrheic athletes, EA, and nonathletes

\begin{tabular}{lllllll}
$\begin{array}{l}\text { OAA } \\
(\mathrm{n}=43)\end{array}$ & EA & $\mathrm{NA}$ & $\mathrm{p}$ & $\mathrm{p}$ & $\mathrm{p}$ & $\mathrm{p}$ \\
$(\mathrm{n}=24)$ & $(\mathrm{n}=23)$ & & OAA vs. EA & OAA vs. NA & EA vs. NA \\
\hline
\end{tabular}

\begin{tabular}{|c|c|c|c|c|c|c|c|}
\hline \multicolumn{8}{|l|}{ Hemodynamic characteristics } \\
\hline $\mathrm{SBP}, \mathrm{mm} \mathrm{Hg}$ & $100.4(8.7)$ & $107.5(6.7)$ & $103.0(7.9)$ & 0.003 & 0.002 & - & - \\
\hline $\mathrm{DBP}, \mathrm{mm} \mathrm{Hg}$ & $66.6(7.6)$ & $67.2(7.3)$ & $66.0(6.9)$ & NS & - & - & - \\
\hline Pulse pressure, $\mathrm{mm} \mathrm{Hg}$ & $33.7(6.2)$ & $40.3(6.4)$ & $36.9(7.5)$ & 0.001 & 0.0006 & - & - \\
\hline Temperature, ${ }^{\circ} \mathrm{F}$ & $97.6(0.9)$ & $98.4(0.6)$ & $98.4(0.9)$ & 0.0002 & 0.002 & 0.001 & - \\
\hline \multicolumn{8}{|l|}{ Hematological characteristics } \\
\hline Hemoglobin, g/dl & $13.1(0.9)$ & $13.2(1.0)$ & $13.1(0.7)$ & NS & - & - & - \\
\hline Hematocrit, \% & $38.6(2.9)$ & $39.2(3.4)$ & $38.8(2.0)$ & NS & - & - & - \\
\hline $\mathrm{MCV}, \mathrm{fl}$ & $91.1(5.3)$ & $90.7(6.2)$ & $89.2(3.2)$ & NS & - & - & - \\
\hline $\mathrm{MCH}, \mathrm{pg}$ & $30.8(1.9)$ & $30.6(2.2)$ & $30.1(1.2)$ & NS & - & - & - \\
\hline $\mathrm{MCHC}, \mathrm{g} / \mathrm{dl}$ & $33.9(0.8)$ & $33.8(1.3)$ & $33.8(0.9)$ & NS & - & - & - \\
\hline RDW, \% & $13.5(1.0)$ & $13.2(0.7)$ & $13.4(0.7)$ & NS & - & - & - \\
\hline Albumin, mg/dl & $4.6(0.3)$ & $4.5(0.2)$ & $4.5(0.2)$ & NS & - & - & - \\
\hline Total bilirubin, mg/dl & $0.4(0.3)$ & $0.4(0.2)$ & $0.4(0.2)$ & NS & - & - & - \\
\hline Direct bilirubin, mg/dl & $0.1(0.1)$ & $0.1(0.1)$ & $0.1(0.04)$ & NS & - & - & - \\
\hline Alkaline phosphatase ${ }^{\mathrm{a}}, \mathrm{U} / \mathrm{l}$ & $70.1(23.4)$ & $72.8(17.3)$ & $63.0(16.6)$ & NS & - & - & - \\
\hline $\mathrm{AST}^{\mathrm{a}}, \mathrm{U} / \mathrm{l}$ & $26.5(9.0)$ & $26.7(10.3)$ & $18.6(4.4)$ & 0.0001 & - & $<0.0001$ & 0.0008 \\
\hline $\mathrm{ALT}^{\mathrm{a}}, \mathrm{U} / \mathrm{l}$ & $23.7(12.6)$ & $16.7(7.7)$ & $14.0(4.8)$ & $<0.0001$ & 0.0006 & $<0.0001$ & - \\
\hline
\end{tabular}

Values are expressed as means (SD). $\mathrm{MCV}=$ Mean corpuscular volume; $\mathrm{MCH}=$ mean corpuscular hemoglobin; $\mathrm{MCHC}=$ mean corpuscular hemoglobin concentration; RDW = red cell distribution width. ${ }^{\text {a }}$ Nonparametric testing.

found between activity level and SBP, DBP, or pulse pressure. Temperature was lower in OAA than in EA and nonathletes, and it was not affected by the date of screening (seasonal variation).

Groups did not differ in terms of hematological parameters, albumin, or total protein. However, $3 \mathrm{OAA}$ and 2 EA had hematocrit $<34.8 \%$ (mean -2 SD for controls). Aspartate aminotransferase (AST) was elevated in both groups of athletes compared to nonathletes, and alanine aminotransferase (ALT) was higher in OAA versus EA and nonathletes; $9.3,8.7$, and $0 \%$ of OAA, EA, and nonathletes, respectively, had AST levels above the normal range, and 18.6, 0 , and $0 \%$ of OAA, EA, and nonathletes, respectively, had ALT levels above the normal range. After adjusting for hours/week of athletic activity, the difference in AST across groups was not significant. However, ALT remained higher in OAA compared to the other groups. Total bilirubin, direct bilirubin, and alkaline phosphatase did not differ among groups.

Clinical Characteristics of Young OAA
Determinants of Hemodynamic, Hematological, and Biochemical Parameters

SBP and DBP were positively associated with BMI (table 3 ). Heart rate was positively associated with percent body fat and total, trunk, and extremity fat and inversely associated with lean mass and athletic activity. Duration of amenorrhea inversely predicted SBP, pulse pressure, heart rate, and temperature.

AST and ALT were associated inversely with fat stores (percent body fat and total, trunk, and extremity fat) and positively with athletic activity level, with AST having a stronger correlation than ALT. We found a positive association between AST and total and extremity lean mass. In addition, menarchal age and amenorrhea duration were positive predictors of liver enzymes. WBC counts were positively associated with BMI $(r=0.23, p=0.03)$, whereas $\mathrm{RBC}$ counts were inversely associated with duration of amenorrhea $(\mathrm{r}=$ $-0.29, \mathrm{p}=0.006$ ). 
Table 3. Correlations of body composition with hemodynamic parameters and liver enzymes

\begin{tabular}{|c|c|c|c|c|c|c|c|c|c|c|c|c|c|c|}
\hline & \multicolumn{2}{|l|}{ SBP } & \multicolumn{2}{|c|}{ DBP } & \multicolumn{2}{|c|}{ Pulse pressure } & \multicolumn{2}{|l|}{ Pulse } & \multicolumn{2}{|c|}{ Temperature } & \multicolumn{2}{|l|}{ AST } & \multicolumn{2}{|l|}{ ALT } \\
\hline & $\mathrm{r}$ & $\mathrm{p}$ & $\mathrm{r}$ & $\mathrm{p}$ & $\mathrm{r}$ & $\mathrm{p}$ & $r$ & $\mathrm{p}$ & $\mathrm{r}$ & $\mathrm{p}$ & $\mathrm{r}$ & $\mathrm{p}$ & $\mathrm{r}$ & $\mathrm{p}$ \\
\hline Menarchal age, years & 0.02 & - & 0.0 & - & -0.06 & - & -0.16 & - & -0.16 & - & 0.28 & 0.009 & 0.24 & 0.02 \\
\hline $\begin{array}{l}\text { Duration of amenorrhea, } \\
\text { months }\end{array}$ & -0.25 & 0.02 & 0.04 & - & -0.39 & 0.0003 & -0.23 & 0.04 & -0.27 & 0.01 & 0.24 & 0.03 & 0.38 & 0.0003 \\
\hline Athletic activity, h/week & 0.11 & - & 0.07 & - & 0.07 & - & -0.36 & 0.0006 & -0.18 & - & 0.38 & 0.0002 & 0.26 & 0.01 \\
\hline $\mathrm{BMI}, \mathrm{kg} / \mathrm{m}^{2}$ & 0.30 & 0.005 & 0.32 & 0.003 & 0.06 & - & 0.17 & - & 0.16 & - & -0.07 & - & -0.15 & - \\
\hline Percent body fat & 0.04 & - & 0.17 & - & -0.09 & - & 0.37 & 0.0002 & 0.15 & - & -0.44 & $<0.0001$ & -0.33 & 0.001 \\
\hline Total fat, $\mathrm{kg}$ & 0.10 & - & 0.19 & - & -0.06 & - & 0.28 & 0.008 & 0.11 & - & -0.35 & 0.0008 & -0.31 & 0.003 \\
\hline Trunk fat, kg & 0.09 & - & 0.21 & 0.046 & -0.08 & - & 0.24 & 0.02 & 0.05 & - & -0.31 & 0.003 & -0.24 & 0.02 \\
\hline Extremity fat, $\mathrm{kg}$ & 0.13 & - & 0.17 & - & -0.01 & - & 0.33 & 0.002 & 0.19 & 0.08 & -0.36 & 0.0005 & -0.36 & 0.0005 \\
\hline Total lean mass, $\mathrm{kg}$ & 0.06 & - & 0.05 & - & -0.03 & - & -0.32 & 0.003 & -0.12 & - & 0.28 & 0.008 & 0.19 & 0.07 \\
\hline $\begin{array}{l}\text { Total extremity } \\
\quad \text { lean mass, } \mathrm{kg}\end{array}$ & 0.10 & - & 0.10 & - & -0.03 & - & -0.25 & 0.02 & -0.09 & - & 0.25 & 0.02 & 0.14 & - \\
\hline
\end{tabular}

$\mathrm{p}$ values $\leq 0.1$ are reported. Spearman's correlations are reported.

Reported differences among groups remained significant after controlling for athletic activity, percent body fat, lean mass, and amenorrhea duration. Significant predictors of AST were subject group (EA and OAA vs. nonathletes) and percent body fat, contributing to $24 \%$ of the variability. The only predictor for ALT was subject group (OAA vs. EA and nonathletes), explaining $16 \%$ of the variability.

\section{Discussion}

With increasing participation of young women in athletics, there is increasing awareness of the female athlete triad, a key component of which is suboptimal energy availability, leading to menstrual dysfunction. All cellular processes including growth, thermoregulation, and reproduction require energy, and in energy deficit states the available energy is directed towards crucial life-sustaining functions such as temperature and glucose homeostasis. This is consistent with extreme energy depletion (as in AN) causing alterations in hemodynamic, hematological, and biochemical parameters [8]. We report differences in body composition, hemodynamic, and biochemical parameters in normal-weight adolescent OAA compared to EA and nonathletes.

\section{Regional Body Composition}

EA had a lower percent body fat and a higher lean mass than nonathletes, consistent with the known effects of endurance training on body composition [20]. Disordered eating is common in athletes [21], and with excessive exercise it increases the risk of low energy availability. Thirty-five percent of our normal-weight OAA reported disordered eating, which may explain the lower BMI and percent ideal body weight in OAA compared to EA (though OAA did not differ from nonathletes). Moreover, OAA had lower total and regional fat than the other groups, indicative of an overall reduction in energy stores (despite a normal weight).

Interestingly, after controlling for total fat, OAA had higher trunk fat and trunk/extremity fat than EA and nonathletes, suggestive of a central fat redistribution in normal-weight OAA. This is in contrast to low-weight AN girls who have reductions in trunk fat and trunk/extremity fat relative to total fat $[8,22]$. Thus, the severe energy depletion (as in $\mathrm{AN}$ ) that causes severe weight loss likely has a different effect on fat distribution than less severe energy depletion where weight is preserved (as in normal-weight OAA). In a previous study, we reported that OAA have higher cortisol than EA and nonathletes [23]. Because increased cortisol favors central adiposity $[24,25]$, it is possible that trunk fat redistribution in OAA is at least partially mediated by increased cortisol. This is consistent with the increased trunk fat reported following weight gain in women with AN with higher baseline cortisol levels [26-28]. The absence of truncal adiposity in active AN (despite high cortisol) is likely from direct lipolytic effects of increased growth hormone (from low IGF-1 and reduced negative feedback) [27, 29]. Normalweight OAA do not have the marked reductions in IGF-1 seen in $\mathrm{AN}[8,30]$, and thus growth hormone levels are 
likely not as high as in AN. We did not assess cortisol associations with body composition, and this warrants further investigation.

\section{Hemodynamic Parameters}

Long-term endurance exercise decreases the heart rate and blood pressure $[11,31]$ due to intrinsic cardiac remodeling and increased parasympathetic tone [32]. Our findings are consistent in that EA and OAA had a lower heart rate than nonathletes. Heart rate was inversely associated with activity [33] and positively associated with body fat, which may indicate an adaptation to conserve energy rather than a physiological response to exercise.

Exercise has the beneficial effect of lowering blood pressure by reducing vascular resistance and decreasing sympathetic activity $[11,12]$. Studies have reported a lower SBP in adult OAA compared to EA $[9,34]$. In our study, OAA had a lower SBP than EA; however, this was not associated with activity. A difference in SBP among normal-weight young athletes with similar athletic activity (OAA and EA) suggests that factors other than exercise may drive the hemodynamic response in OAA. Heart rate and blood pressure are predicted by body fat in $\mathrm{AN}$, a state of extreme energy deficit [8]. However, we found no association between fat mass and SBP in normalweight athletes and nonathletes. We did find an inverse association between SBP and duration of amenorrhea, consistent with reported associations of hypoestrogenism, with a lower blood pressure and heart rate in exercisers [9]. Thus, the low SBP in OAA may be mediated by menstrual dysfunction and hypoestrogenism rather than by exercise or nutritional deficit.

To our knowledge, this is the first study to assess associations of oligo-amenorrhea and lower fat stores with body temperature in OAA. Klentrou et al. [35] showed that thermoregulation was affected by hormonal status and fat mass in premenarcheal and eumenorrheic young girls. We found lower temperatures in OAA versus EA and nonathletes associated with amenorrhea duration, suggesting efforts towards energy conservation in OAA.

\section{Resting Energy Expenditure}

EA had higher REE than OAA and nonathletes, even after controlling for lean mass. In nonathletes, an inverse association is expected between REE and parasympathetic activity [36], whereas in athletes, a paradoxical positive association is reported, implying higher REE at lower heart rates and blood pressures [13]. In our study, EA demonstrated athletic adaptive changes (a higher REE with a lower heart rate), indicating optimum exercise benefits. In contrast, despite a normal weight, similar activity, and enhanced parasympathetic activity, OAA had lower REE than EA, likely an additional adaptive measure to conserve energy and prevent weight loss.

\section{Hematological Parameters}

Information about hematologic changes in adolescent regular training athletes is limited. One study reported abnormal findings during routine screening in $51 \%$ of athletes, such as reduced hematocrit and increased WBC counts [37]. In fact, dilutional pseudoanemia is a common finding in adult elite endurance athletes consequent to plasma volume expansion [15]. We did not find differences in hematological parameters among groups, which may reflect the younger age of our subjects or a lower intensity of training. This differed from AN girls, who have alterations in many hematological parameters associated with lower BMI [8]. In our study, OAA had WBC counts within the low normal range were positively associated with BMI. There is evidence of transitory leukocytosis and decreased hematocrit following intense short-term exercise; however, long-term alterations have not been reported $[38,39]$. We conclude that chronic exercise and oligo-amenorrhea in young athletes do not affect hematological parameters when weight is preserved.

\section{Biochemical Parameters}

We also assessed associations of endurance training, hypogonadism, and low body fat with liver enzymes. Aminotransferases are markers of liver injury; ALT elevation is more specific to hepatic cell damage, whereas AST may increase with muscular injury as in myocardial infarction or myolysis [40]. One study reported increased AST (27\%) and bilirubin (12\%) during routine biochemical screening in elite athletes [16]. Intense short-term exercise can cause AST elevation (sparing ALT) [41]; however, the effects of chronic exercise on liver enzymes remain unclear. In addition, elevated liver enzymes have been reported in AN consequent to malnutrition [7, 18], and inverse associations of ALT and GGT with BMI and body fat have been found [42]. We thus expected elevated AST in athletes related to activity, and elevated ALT in OAA from energy depletion (indicated by lower body fat).

Consistent with our expectations, AST was elevated in both groups of athletes compared to nonathletes, and ALT (more predictive of hepatocyte injury) was higher in OAA than in EA and nonathletes. In fact, $18.6 \%$ of OAA had ALT levels above normal. Differences between groups 
persisted after controlling for confounders. Both transaminases were inversely associated with body fat in normal-weight subjects, consistent with data in AN [42]. In a regression model, body fat and being an athlete (OAA and EA vs. nonathletes) were predictors of AST, while being amenorrheic (OAA vs. EA and nonathletes) was the only predictor of ALT. AST had a stronger association with activity level, and ALT with amenorrhea duration. We thus speculate that ALT elevations are related to the nutritional and hormonal state of OAA (low fat stores and amenorrhea duration), whereas AST elevations are from the muscular workload (athletic activity). This indicates that ALT elevations are more concerning in athletes than AST elevations and suggest poorer nutrition and a risk of hypogonadism.

In conclusion, athletic activity is associated with lower body fat and heart rate and elevated AST. Oligo-amenorrhea is associated with reductions in body fat, SBP, and body temperature and elevations in ALT. Our data sug- gest that body weight provides limited information about nutritional status in athletes. OAA may have altered metabolic and endocrine function despite being normal weight and need careful monitoring of hemodynamic parameters and liver enzymes. A trend over time of decreasing heart rate and increasing liver enzymes may indicate reductions in body fat (and thus energy stores) and should trigger discussions of caloric intake to keep pace with the exercise energy expenditure.

\section{Acknowledgement}

This work was supported by NIH grants 1R01 HD060827, K24 HD07184, and 5UL1 RR025758.

\section{Disclosure Statement}

The authors have no conflicts of interest to disclose.

\section{References}

1 National Federation of State High School Associations: $2011-12$ high school athletics participation survey. Indianapolis, NFHS, 2012, pp 1-16.

2 Temme KE, Hoch AZ: Recognition and rehabilitation of the female athlete triad/tetrad: a multidisciplinary approach. Curr Sports Med Rep 2013;12:190-199.

-3 Nazem TG, Ackerman KE: The female athlete triad. Sports Health 2012;4:302-311.

4 Nattiv A, Loucks AB, Manore MM, Sanborn CF, Sundgot-Borgen J, Warren MP; American College of Sports Medicine: American college of sports medicine position stand: the female athlete triad. Med Sci Sports Exerc 2007;39: 1867-1882.

5 Nichols JF, Rauh MJ, Lawson MJ, Ji M, Barkai HS: Prevalence of the female athlete triad syndrome among high school athletes. Arch Pediatr Adolesc Med 2006;160:137-142.

$\checkmark 6$ Lal S, Hoch AZ: Factors that affect the young female athlete. Phys Med Rehabil Clin N Am 2007;18:361-383, vii.

7 Miller KK, Grinspoon SK, Ciampa J, Hier J, Herzog D, Klibanski A: Medical findings in outpatients with anorexia nervosa. Arch Intern Med 2005;165:561-566.

8 Misra M, Aggarwal A, Miller KK, Almazan C, Worley M, Soyka LA, Herzog DB, Klibanski A: Effects of anorexia nervosa on clinical, hematologic, biochemical, and bone density parameters in community-dwelling adolescent girls. Pediatrics 2004;114:1574-1583.

-9 O’Donnell E, Harvey PJ, Goodman JM, De Souza MJ: Long-term estrogen deficiency lowers regional blood flow, resting systolic blood pressure, and heart rate in exercising premenopausal women. Am J Physiol Endocrinol Metab 2007;292:E1401-E1409.

10 Ackerman KE, Davis B, Jacoby L, Misra M: DXA surrogates for visceral fat are inversely associated with bone density measures in adolescent athletes with menstrual dysfunction. J Pediatr Endocrinol Metab 2011;24:497504.

$\checkmark 11$ Cornelissen VA, Fagard RH: Effects of endurance training on blood pressure, blood pressure-regulating mechanisms, and cardiovascular risk factors. Hypertension 2005;46:667675.

12 Varga-Pinter B, Horvath P, Kneffel Z, Major Z, Osvath P, Pavlik G: Resting blood pressure values of adult athletes. Kidney Blood Press Res 2011;34:387-395.

13 Messina G, Vicidomini C, Viggiano A, Tafuri D, Cozza V, Cibelli G, Devastato A, De Luca B, Monda M: Enhanced parasympathetic activity of sportive women is paradoxically associated to enhanced resting energy expenditure. Auton Neurosci 2012;169:102106.

14 Palla B, Litt IF: Medical complications of eating disorders in adolescents. Pediatrics 1988; 81:613-623.

15 Shaskey DJ, Green GA: Sports haematology. Sports Med 2000;29:27-38.

16 Fallon KE: The clinical utility of screening of biochemical parameters in elite athletes: analysis of 100 cases. Br J Sports Med 2008;42: 334-337.

17 Ruhl CE, Everhart JE: Trunk fat is associated with increased serum levels of alanine amino- transferase in the United States. Gastroenterology 2010;138:1346-1356, 1356.e1-1356.e3.

18 Hanachi M, Melchior JC, Crenn P: Hypertransaminasemia in severely malnourished adult anorexia nervosa patients: risk factors and evolution under enteral nutrition. Clin Nutr 2013;32:391-395.

19 Greulich W, Pyle S: Radiographic Atlas of Skeletal Development of the Hand and Wrist. Stanford, Stanford University Press, 1959.

20 Carbuhn AF, Fernandez TE, Bragg AF, Green JS, Crouse SF: Sport and training influence bone and body composition in women collegiate athletes. J Strength Cond Res 2010;24: 1710-1717.

21 De Souza MJ, Williams NI: Physiological aspects and clinical sequelae of energy deficiency and hypoestrogenism in exercising women. Hum Reprod Update 2004;10:433448.

22 Kerruish KP, O’Connor J, Humphries IR, Kohn MR, Clarke SD, Briody JN, Thomson EJ, Wright KA, Gaskin KJ, Baur LA: Body composition in adolescents with anorexia nervosa. Am J Clin Nutr 2002;75:31-37.

23 Ackerman KE, Patel KT, Guereca G, Pierce L, Herzog DB, Misra M: Cortisol secretory parameters in young exercisers in relation to $\mathrm{lh}$ secretion and bone parameters. Clin Endocrinol (Oxf) 2013;78:114-119.

24 Duclos M, Gatta B, Corcuff JB, Rashedi M, Pehourcq F, Roger P: Fat distribution in obese women is associated with subtle alterations of the hypothalamic-pituitary-adrenal axis activity and sensitivity to glucocorticoids. Clin Endocrinol (Oxf) 2001;55:447-454. 
25 Wajchenberg BL, Bosco A, Marone MM, Levin S, Rocha M, Lerario AC, Nery M, Goldman J, Liberman B: Estimation of body fat and lean tissue distribution by dual energy X-ray absorptiometry and abdominal body fat evaluation by computed tomography in Cushing's disease. J Clin Endocrinol Metab 1995; 80:2791-2794.

-26 Grinspoon S, Thomas L, Miller K, Pitts S, Herzog D, Klibanski A: Changes in regional fat redistribution and the effects of estrogen during spontaneous weight gain in women with anorexia nervosa. Am J Clin Nutr 2001; 73:865-869.

27 Wassif WS, Ross AR: Steroid metabolism and excretion in anorexia nervosa. Vitam Horm 2013;92:125-140.

-28 Misra M, Soyka LA, Miller KK, Grinspoon S, Levitsky LL, Klibanski A: Regional body composition in adolescents with anorexia nervosa and changes with weight recovery. Am J Clin Nutr 2003;77:1361-1367.

29 Misra M, Miller KK, Almazan C, Worley M, Herzog DB, Klibanski A: Hormonal determinants of regional body composition in adolescent girls with anorexia nervosa and controls. J Clin Endocrinol Metab 2005;90:2580-2587.
0 Christo K, Prabhakaran R, Lamparello B, Cord J, Miller KK, Goldstein MA, Gupta N, Herzog DB, Klibanski A, Misra M: Bone metabolism in adolescent athletes with amenorrhea, athletes with eumenorrhea, and control subjects. Pediatrics 2008;121:1127-1136.

31 Wilmore JH, Stanforth PR, Gagnon J, Rice T, Mandel S, Leon AS, Rao DC, Skinner JS, Bouchard C: Heart rate and blood pressure changes with endurance training: the HERITAGE Family Study. Med Sci Sports Exerc 2001;33:107-116.

32 Scott AS, Eberhard A, Ofir D, Benchetrit G, Dinh TP, Calabrese P, Lesiuk V, Perrault H: Enhanced cardiac vagal efferent activity does not explain training-induced bradycardia. Auton Neurosci 2004;112:60-68.

33 Grant CC, Mongwe L, Janse van Rensburg DC, Fletcher L, Wood PS, Terblanche E, du Toit P, Grant TC: The difference between exercise induced autonomic and fitness changes measured after 12 weeks and 20 weeks of medium to high intensity military training. J Strength Cond Res 2013, E-pub ahead of print.

34 O'Donnell E, Goodman JM, Harvey PJ: Clinical review: cardiovascular consequences of ovarian disruption - a focus on functional hypothalamic amenorrhea in physically active women. J Clin Endocrinol Metab 2011;96: 3638-3648.

-35 Klentrou P, Cunliffe M, Slack J, Wilk B, BarOr O, De Souza MJ, Plyley M: Temperature regulation during rest and exercise in the cold in premenarcheal and menarcheal girls. J Appl Physiol 2004;96:1393-1398.
36 Romijn JA, Fliers E: Sympathetic and parasympathetic innervation of adipose tissue: metabolic implications. Curr Opin Clin Nutr Metab Care 2005;8:440-444.

37 Fallon KE: Utility of hematological and ironrelated screening in elite athletes. Clin J Sport Med 2004;14:145-152.

38 Banfi G, Lundby C, Robach P, Lippi G: Seasonal variations of haematological parameters in athletes. Eur J Appl Physiol 2011;111: 9-16.

39 Lippi G, Banfi G, Montagnana M, Salvagno GL, Schena F, Guidi GC: Acute variation of leucocytes counts following a half-marathon run. Int J Lab Hematol 2010;32:117-121.

40 Banfi G, Colombini A, Lombardi G, Lubkowska A: Metabolic markers in sports medicine. Adv Clin Chem 2012;56:1-54.

41 Banfi G, Morelli P: Relation between body mass index and serum aminotransferases concentrations in professional athletes. J Sports Med Phys Fitness 2008;48:197-200.

42 Fong HF, Divasta AD, Difabio D, Ringelheim J, Jonas MM, Gordon CM: Prevalence and predictors of abnormal liver enzymes in young women with anorexia nervosa. J Pediatr 2008;153:247-253. 